\title{
Methane prediction based on individual or groups of milk fatty acids for dairy cows fed rations with or without linseed
}

\author{
Stefanie W. Engelke, ${ }^{1}$ Gürbüz Daş, ${ }^{1}$ Michael Derno, ${ }^{1}$ Armin Tuchscherer, ${ }^{2}$ Klaus Wimmers, ${ }^{3}$ Michael Rychlik, ${ }^{4}$ \\ Hermine Kienberger, ${ }^{5}$ Werner Berg, ${ }^{6}$ Björn Kuhla, ${ }^{1}$ and Cornelia C. Metges ${ }^{1,7 *}$ \\ ${ }^{1}$ Institute of Nutritional Physiology "Oskar Kellner," Leibniz Institute for Farm Animal Biology (FBN), Wilhelm-Stahl-Allee 2, 18196 Dummerstorf, \\ Germany \\ ${ }^{2}$ Institute of Genetics and Biometry, Leibniz Institute for Farm Animal Biology (FBN), Wilhelm-Stahl-Allee 2, 18196 Dummerstorf, Germany \\ ${ }^{3}$ Institute of Genome Biology, Leibniz Institute for Farm Animal Biology (FBN), Wilhelm-Stahl-Allee 2, 18196 Dummerstorf, Germany \\ ${ }^{4}$ Analytical Food Chemistry, Technical University of Munich, Maximus-von-Imhof-Forum, 85354 Freising, Germany \\ ${ }^{5}$ Bavarian Center for Biomolecular Mass Spectrometry, Gregor-Mendel-Strasse 4, 85354 Freising, Germany \\ ${ }^{6}$ Department of Technology Assessment and Substance Cycles, Leibniz Institute for Agricultural Engineering and Bioeconomy (ATB), \\ Max-Eyth-Allee 100, 14469 Potsdam, Germany \\ ${ }^{7}$ Nutritional Physiology and Animal Nutrition, Faculty of Agriculture and Environmental Sciences, University of Rostock, 18059 Rostock, Germany
}

\section{ABSTRACT}

Milk fatty acids (MFA) are a proxy for the prediction of $\mathrm{CH}_{4}$ emission from cows, and prediction differs with diet. Our objectives were (1) to compare the effect of diets on the relation between MFA profile and measured $\mathrm{CH}_{4}$ production, (2) to predict $\mathrm{CH}_{4}$ production based on 6 data sets differing in the number and type of MFA, and (3) to test whether additional inclusion of energy-corrected milk (ECM) yield or dry matter intake (DMI) as explanatory variables improves predictions. Twenty dairy cows were used. Four diets were used based on corn silage (CS) or grass silage (GS) without (L0) or with linseed (LS) supplementation. Ten cows were fed CS-L0 and CS-LS and the other 10 cows were fed GS-L0 and GS-LS in random order. In feeding wk 5 of each diet, $\mathrm{CH}_{4}$ production $(\mathrm{L} / \mathrm{d})$ was measured in respiration chambers for $48 \mathrm{~h}$ and milk was analyzed for MFA concentrations by gas chromatography. Specific $\mathrm{CH}_{4}$ prediction equations were obtained for L0-, LS-, GS-, and CS-based diets and for all 4 diets collectively and validated by an internal cross-validation. Models were developed containing either 43 identified MFA or a reduced set of 7 groups of biochemically related MFA plus C16:0 and C18:0. The $\mathrm{CS}$ and LS diets reduced $\mathrm{CH}_{4}$ production compared with GS and L0 diets, respectively. Methane yield (L/ $\mathrm{kg}$ of DMI) reduction by LS was higher with CS than GS diets. The concentrations of C18:1 trans and n-3 MFA differed among GS and CS diets. The LS diets

Received April 11, 2018.

Accepted October 25, 2018.

*Corresponding author: metges@fbn-dummerstorf.de resulted in a higher proportion of unsaturated MFA at the expense of saturated MFA. When using the data set of 43 individual MFA to predict $\mathrm{CH}_{4}$ production (L/d), the cross-validation coefficient of determination $\left(\mathrm{R}_{\mathrm{CV}}^{2}\right)$ ranged from 0.47 to 0.92 . When using groups of MFA variables, the $R_{C V}^{2}$ ranged from 0.31 to 0.84 . The fit parameters of the latter models were improved by inclusion of ECM or DMI, but not when added to the data set of 43 MFA for all diets pooled. Models based on GS diets always had a lower prediction potential $\left(\mathrm{R}_{\mathrm{CV}}^{2}=0.31\right.$ to 0.71$)$ compared with data from $\mathrm{CS}$ $\operatorname{diets}\left(\mathrm{R}_{\mathrm{CV}}^{2}=0.56\right.$ to 0.92$)$. Models based on LS diets produced lower prediction with data sets with reduced MFA variables $\left(\mathrm{R}_{\mathrm{CV}}^{2}=0.62\right.$ to 0.68$)$ compared with $\mathrm{L} 0 \operatorname{diets}\left(\mathrm{R}_{\mathrm{CV}}^{2}=0.67\right.$ to 0.80$)$. The MFA C18:1 cis-9 and $\mathrm{C} 24: 0$ and the monounsaturated FA occurred most often in models. In conclusion, models with a reduced number of MFA variables and ECM or DMI are suitable for $\mathrm{CH}_{4}$ prediction, and $\mathrm{CH}_{4}$ prediction equations based on diets containing linseed resulted in lower prediction accuracy.

Key words: dairy cow, methane emission prediction, methane mitigation, methane proxy, milk fatty acids

\section{INTRODUCTION}

Methane is a greenhouse gas and a product of rumen fermentation (Hristov et al., 2013). Methane production $(\mathrm{L} / \mathrm{d})$ is a heritable trait, and genetic selection for low-emitting cows is a promising mitigation option (Pickering et al., 2015; Negussie et al., 2017). Methane emission quantification in respiration chambers is considered as the gold standard but unsuitable for large-scale individual animal measurements (Hammond et al., 2016; Patra, 2016). One promising proxy for the prediction of $\mathrm{CH}_{4}$ production is the concentration of 
milk fatty acids (MFA; van Gastelen and Dijkstra, 2016; Negussie et al., 2017). Dietary composition affects the relationship between MFA and $\mathrm{CH}_{4}$ emission parameters (Mohammed et al., 2011; Dijkstra et al., 2016; Rico et al., 2016). Milk fatty acids synthesized de novo are predominantly generated from rumen acetate and BHB (Shingfield et al., 2013), which are derived from fiber fermentation, and they are positively associated with ruminal $\mathrm{CH}_{4}$ production (Shingfield et al., 2013; Castro-Montoya et al., 2016a). Forage type in ruminant diets can affect $\mathrm{CH}_{4}$ production as well as MFA pattern (Beauchemin et al., 2008; Hart et al., 2015; van Gastelen et al., 2015). Likewise, a high starch content favors propionate synthesis, which consumes fermentative hydrogen and can thus reduce $\mathrm{CH}_{4}$ production (Hook et al., 2010; Knapp et al., 2014). The MFA groups of long-chain MUFA and PUFA and the individual C18:0 originate from plant fat-derived UFA (Ferlay et al., 2013; Kliem and Shingfield, 2016; Meignan et al., 2017) are either directly transferred into milk fat (e.g., C18:3n-3) or influence rumen fermentation, thereby altering the pattern and level of precursors for MFA synthesis and affect the postabsorptive lipid metabolism (de novo MFA synthesis, saturation or desaturation rates, or FA elongation; Angulo et al., 2012; Lanier and Corl, 2015; Meignan et al., 2017). In addition, dietary fat-associated decreases of fiber degradability and toxic effects of PUFA on archaea reduce $\mathrm{CH}_{4}$ production (Maia et al., 2007; Benchaar et al., 2015). Furthermore, fat supplements can also affect DMI and, thus, net production of short-chain MFA.

Several authors have used MFA concentrations to develop $\mathrm{CH}_{4}$ prediction equations that differ in type and numbers of explanatory MFA (e.g., van Lingen et al., 2014; Castro-Montoya et al., 2016b; Rico et al., 2016). For example, van Lingen et al. (2014) developed $\mathrm{CH}_{4}$ predictions based on 21 individual and 3 groups of MFA concentrations, whereas Rico et al. (2016) included 83 individual MFA and sums of different MFA proportions. van Gastelen and Dijkstra (2016) pointed out that only $\mathrm{C} 17: 1$ cis-9 and $\mathrm{C} 18: 1$ cis-11 appeared in 2 or more of the prediction equations published, indicating that explanatory MFA are extremely diverse, which likely is a consequence of differences in diet composition (Dijkstra et al., 2011; Mohammed et al., 2011; Rico et al., 2016). We were interested to know how prediction equations change when the MFA data changes in the number of variables and whether individual MFA or groups of related MFA are used.

It has been also discussed whether the combination of MFA concentrations with additional explanatory parameters would improve prediction (Castro-Montoya et al., 2016b; Negussie et al., 2017; van Gastelen et al.,
2017). The DMI of cows is known as the main determinant for $\mathrm{CH}_{4}$ production (Knapp et al., 2014), and DMI is associated with milk yield (Hristov et al., 2013). Consequently, milk yield could be a potential alternative for DMI as a variable in prediction equations (Hristov et al., 2013; Negussie et al., 2017). We have reported that a prediction equation based on MFA, determined by mid-infrared spectroscopy, which contained DMI as an additional explanatory variable, showed a similar coefficient of determination when DMI was replaced by ECM (Engelke et al., 2018).

Thus, our hypothesis was that $\mathrm{CH}_{4}$ prediction equations based on MFA depend on the number of MFA or MFA group variables, and that inclusion of DMI or ECM together with MFA improves prediction equations. Hence, the objectives of this study were (1) to determine the effect of dietary composition on the relationship between MFA concentrations and $\mathrm{CH}_{4}$ production, with special emphasis on the effect of linseed supplementation; (2) to compare $\mathrm{CH}_{4}$ prediction models based on differently sized and composed MFA data sets; and (3) to test whether the inclusion of DMI or ECM in addition to MFA concentrations as variable improves prediction.

\section{MATERIALS AND METHODS}

\section{Animals, Experimental Design, and Diets}

The procedures performed in our study were in agreement with the German Animal protection law and approved by the relevant authority (Landesamt für Landwirtschaft, Lebensmittelsicherheit und Fischereiwesen Mecklenburg-Vorpommern, Germany; permission no. 7221.3-1-014/14). Twenty lactating German Holstein cows $(106 \pm 28 \mathrm{DIM}, 29.5 \pm 7.7 \mathrm{~kg}$ of $\mathrm{ECM} / \mathrm{d}$, $580 \pm 57 \mathrm{~kg}$ of BW; mean $\pm \mathrm{SD}$ ), of which 15 cows were in second and 5 cows were in third lactation, were purchased from a dairy farm located in the region of Mecklenburg-Western Pomerania, Germany. All cows were sired by 1 bull (Omega 802670; Rinderzucht Mecklenburg-Vorpommern GmbH, Woldegk, Germany). Cows were kept in tiestalls, had free access to water, and were offered a TMR for ad libitum intake. Milking occurred at 0630 and $1630 \mathrm{~h}$. To produce a wide range of $\mathrm{CH}_{4}$ production values, we used 2 basal TMR, which were composed close to what is commonly used in German dairy farming. The major forage component was either corn silage (CS) or grass silage (GS), supplemented with $(\mathbf{L S})$ or without linseed (L0; Table 1). Diets contained grass silage and corn silage at DM levels of 130 and $450 \mathrm{~g} / \mathrm{kg}$ (CS) or 360 and $190 \mathrm{~g} / \mathrm{kg}$ (GS), respectively. The LS diets contained $60 \mathrm{~g}$ of fat/ 
$\mathrm{kg}$ of DM, whereas the L0 diets had $30 \mathrm{~g}$ of fat $/ \mathrm{kg}$ of DM. The diets had the same target energy level of $7 \mathrm{MJ}$ of $\mathrm{NE}_{\mathrm{L}} / \mathrm{kg}$ of $\mathrm{DM}$, which was achieved by replacing the linseed product with an isoenergetic amount of starch in the TMR. Forage-to-concentrate ratio differed from 66:34 (GS-L0), 73:27 (GS-LS), 65:35 (CS-L0), to 68:32 (CS-LS). We randomly selected 5 of the 20 cows to be fed the CS-L0 diet in the first 5-wk period (period A) and the CS-LS diet in the second 5-wk period (period B), whereas we randomly selected 5 other cows to be fed the CS-LS diet during the first 5 -wk period and CS-L0 diet during the second 5 -wk period. Another 5 cows were fed GS-L0 diet first and GS-LS diet second, whereas the remaining 5 cows were given the opposite treatments. The transition from the standard diet to an experimental diet or from one experimental diet to the other was made over $5 \mathrm{~d}$ in experimental week (EW) 0 and 6 , respectively, in a step-wise fashion by replacing $20,40,60,80$, and $100 \%$ of DM of the standard diet by the experimental diet. The study was conducted in 5 experimental blocks. Each block ran over a total of 12 EW and included 4 cows, all 4 diets, and 2 periods (A and B). That means 2 cows per each diet were measured within each block. Cows assigned to the CS

Table 1. Ingredients and chemical composition of the experimental TMR consisting of basal rations based largely on grass silage (GS) or corn silage (CS) without (L0) and with (LS) linseed supplementation (means $\pm \mathrm{SD} ; \mathrm{n}=5)$

\begin{tabular}{|c|c|c|c|c|}
\hline \multirow[b]{2}{*}{ Item } & \multicolumn{2}{|c|}{ GS } & \multicolumn{2}{|c|}{ CS } \\
\hline & L0 & LS & L0 & $\mathrm{LS}$ \\
\hline \multicolumn{5}{|l|}{ Ingredient $(\mathrm{g} / \mathrm{kg}$ of $\mathrm{DM})$} \\
\hline Grass silage & $343 \pm 31.0$ & $380 \pm 15.0$ & $122 \pm 21.5$ & $142 \pm 34.3$ \\
\hline Corn silage & $181 \pm 33.2$ & $195 \pm 37.9$ & $445 \pm 46.7$ & $452 \pm 44.0$ \\
\hline Straw, barley & $52.1 \pm 7.0$ & $60.8 \pm 23.2$ & $39.8 \pm 7.2$ & $34.0 \pm 10.3$ \\
\hline Grass hay & $80.8 \pm 12.0$ & $93.5 \pm 22.0$ & $43.2 \pm 3.1$ & $43.5 \pm 3.0$ \\
\hline Corn, ground & - & - & $92.7 \pm 9.2$ & $25.4 \pm 27.2$ \\
\hline Soy extract meal & $25.4 \pm 26.8$ & $40.1 \pm 19.2$ & $114 \pm 14.2$ & $87.1 \pm 9.2$ \\
\hline Barley, ground & $99.5 \pm 17.9$ & - & - & - \\
\hline Wheat, ground & $101 \pm 9.8$ & - & - & - \\
\hline Linseed product ${ }^{1}$ & - & $143 \pm 11.4$ & - & $137 \pm 9.9$ \\
\hline Concentrate $^{2}$ & $109 \pm 19.7$ & $78.4 \pm 13.0$ & $129 \pm 7.3$ & $65.0 \pm 32.6$ \\
\hline Mineral/vitamin $\operatorname{mix}^{3}$ & $9.1 \pm 0.5$ & $9.5 \pm 0.6$ & $10.1 \pm 0.6$ & $10.1 \pm 0.6$ \\
\hline Calcium carbonate $^{4}$ & - & - & $4.1 \pm 0.3$ & $4.1 \pm 0.3$ \\
\hline Grass to corn silage ratio & 1.90 & 1.95 & 0.27 & 0.31 \\
\hline Forage:concentrate ratio & $66: 34$ & $73: 27$ & $65: 35$ & $68: 32$ \\
\hline $\mathrm{DM}\left(\mathrm{g} / \mathrm{kg}\right.$ of $\left.\mathrm{FM}^{5}\right)$ & $468 \pm 33.0$ & $452 \pm 45.0$ & $446 \pm 32.0$ & $439 \pm 33.0$ \\
\hline \multicolumn{5}{|l|}{ Nutrients $(\mathrm{g} / \mathrm{kg}$ of $\mathrm{DM})$} \\
\hline Crude ash & $69.9 \pm 2.8$ & $75.8 \pm 2.5$ & $66.1 \pm 3.0$ & $65.7 \pm 4.2$ \\
\hline $\mathrm{CP}$ & $161 \pm 9.0$ & $173 \pm 14.4$ & $169 \pm 11.7$ & $163 \pm 11.1$ \\
\hline Crude fiber & $166 \pm 7.9$ & $186 \pm 7.1$ & $155 \pm 3.3$ & $161 \pm 4.5$ \\
\hline Crude fat & $28.1 \pm 1.7$ & $58.3 \pm 7.8$ & $29.8 \pm 2.4$ & $56.4 \pm 6.5$ \\
\hline Sugar & $51.3 \pm 15.7$ & $50.1 \pm 16.2$ & $31.4 \pm 7.9$ & $30.3 \pm 11.1$ \\
\hline Starch & $218 \pm 12.0$ & $110 \pm 18.7$ & $261 \pm 25.4$ & $216 \pm 34.5$ \\
\hline $\mathrm{aNDF}^{6}$ & $371 \pm 18.1$ & $410 \pm 12.9$ & $330 \pm 10.9$ & $352 \pm 9.2$ \\
\hline $\mathrm{ADF}$ & $198 \pm 9.8$ & $224 \pm 7.9$ & $186 \pm 5.4$ & $194 \pm 5.0$ \\
\hline $\mathrm{NE}_{\mathrm{L}}(\mathrm{MJ} / \mathrm{kg}$ of $\mathrm{DM})$ & $6.9 \pm 0.2$ & $6.9 \pm 0.1$ & $7.0 \pm 0.1$ & $7.1 \pm 0.1$ \\
\hline
\end{tabular}

${ }^{1}$ Omegalin 60 (Spezialfutter Neuruppin GmbH und Co.KG, Neuruppin, Germany; per kg feed; 88\% DM): 60\% extruded linseed Tradilin and $40 \%$ bran. Composition: $19.5 \%$ CP, $25 \%$ crude fat, $8.5 \%$ crude fiber; fatty acids (\% of fat): $6 \%$ palmitic acid (C16:0), $18.4 \%$ oleic acid (C18:1 cis-9), $18.5 \%$ linoleic acid (C8:2 cis-9,cis-12), $55 \%$ linolenic acid (C18:3 cis-9,cis-12,cis-15), and $12.8 \mathrm{MJ}_{\text {of }} \mathrm{NE}_{\mathrm{L}} / \mathrm{kg}$ of DM.

${ }^{2}$ Concentrate MF 2000 (Vollkraft Mischfutterwerke GmbH, Güstrow, Germany; per kg feed; 88\% DM): 33\% extracted soy meal, $20 \%$ corn, $17 \%$ wheat gluten, $8 \%$ extracted rapeseed meal, $5 \%$ sugar beet pulp, $2 \%$ sodium hydrogen carbonate, $1.3 \%$ calcium carbonate, $0.2 \%$ sodium chloride. Composition: $24 \% \mathrm{CP}, 3.3 \%$ crude fat, $6.2 \%$ crude fiber, $8.4 \%$ crude ash, $0.7 \%$ calcium, $0.5 \%$ phosphorus, $0.65 \%$ sodium, and $7.1 \mathrm{MJ}$ of $\mathrm{NE}_{\mathrm{L}} / \mathrm{kg}$ of DM.

${ }^{3}$ Rinderstolz 9522 Salvana (Tierernährung, Kl.-O. Sparrieshoop, Germany; per kg feed; 88\% DM): 39.3\% calcium carbonate, $21.7 \%$ monocalcium phosphate, $21 \%$ sodium chloride, $11.9 \%$ magnesium oxide, $2 \%$ sugar beet molasses. Composition: $92 \%$ crude ash, $20 \%$ calcium, $8 \%$ sodium, $6 \%$ magnesium, $5 \%$ phosphorus, 1,000,000 IU of vitamin A, 200,000 IU of vitamin $\mathrm{D}_{3}$, and $4500 \mathrm{mg}$ of vitamin $\mathrm{E}$.

${ }^{4}$ Kreidekalk (Spezialfutter Neuruppin GmbH und Co.KG): calcium carbonate; $37 \%$ calcium.

${ }^{5}$ Fresh matter.

${ }^{6} \mathrm{aNDF}=($ amylase $)$ neutral detergent fiber. 
Table 2. Performance and methane emission parameters of cows fed basal rations based on grass silage (GS) or corn silage (CS) with or without linseed supplementation (LS or L0, respectively)

\begin{tabular}{|c|c|c|c|c|c|c|c|c|}
\hline Item & \multicolumn{2}{|c|}{$\mathrm{GS}^{1}$} & \multicolumn{2}{|c|}{$\mathrm{CS}^{1}$} & $\mathrm{SE}$ & \multicolumn{3}{|c|}{$P$-value ${ }^{2}$} \\
\hline DMI (kg/d) & 15.94 & 14.80 & 18.91 & 17.76 & 0.985 & 0.024 & 0.061 & 0.990 \\
\hline Milk fat (\%) & 4.48 & 4.50 & 4.08 & 3.83 & 0.202 & 0.035 & 0.364 & 0.292 \\
\hline \multicolumn{9}{|l|}{$\mathrm{CH}_{4}$ emission parameters } \\
\hline $\mathrm{CH}_{4}$ production $(\mathrm{L} / \mathrm{d})$ & 506.8 & 453.0 & 587.7 & 500.6 & 30.40 & 0.089 & 0.002 & 0.373 \\
\hline
\end{tabular}

${ }^{1} \mathrm{LSM}$.

${ }^{2}$ ANOVA F-test for the effects of basal ration (B), linseed supplementation (L), or their interaction $(\mathrm{B} \times \mathrm{L})$.

and GS diets did not differ in their mean baseline $\mathrm{CH}_{4}$ production (506 and $477 \mathrm{~L} / \mathrm{d}$, respectively; $P=0.441$ ).

To keep feed composition as constant as possible over time, experimental diets were mixed once a week, conserved with $1 \%$ granulated propionic acid (BERGO TMR-stabil G, Bergophor Futtermittelfabrik Dr. Berger GmbH \& Co.KG, Kulmbach, Germany), and vacuum-packaged in thirty 40-kg plastic bags (NeuRo Planen GmbH, Neuendorf, Germany). Cows were fed ad libitum from these bags twice daily at 0730 and 1730 h. Feed intake was recorded daily. Three cows had to be removed in the GS-LS period because of illness or feed refusal. The diet composition was calculated in accordance to recommendations of the German Society of Nutritional Physiology (Gesellschaft für Ernährungsphysiologie, 2001).

\section{Feed Sampling and Analyses}

Feed samples were collected during TMR mixing and stored at $-20^{\circ} \mathrm{C}$. At the end of each experimental block, feed samples were pooled to determine DM. The DM content was determined by drying at $60^{\circ} \mathrm{C}$ for 24 $\mathrm{h}$ and then at $103^{\circ} \mathrm{C}$ for $4 \mathrm{~h}$ (Naumann et al., 1976). Analyses of nutrient composition in feedstuffs (Table 1) were performed according to the Weender standard analysis (Naumann et al., 1976), with modifications by Van Soest et al. (1991), by the accredited feed laboratory of Landwirtschaftliche Untersuchungs-und Forschungsanstalt der LMS Agrarberatung GmbH (LUFA, Rostock, Germany). The energy content $\left(\mathrm{NE}_{\mathrm{L}}\right)$ was calculated according to the German Society of Nutritional Physiology (Gesellschaft für Ernährungsphysiologie, 2001), except for the linseed product Omegalin 60 (Spezialfutter Neuruppin GmbH und Co. KG, Neuruppin, Germany) and concentrate MF 2000 (Vollkraft Mischfutterwerke GmbH, Güstrow, Germany), which were analyzed according to German feed regulations (Ger- man Federal Law Gazette, 1981) §13 by LUFA. Nutrient intake of cows was calculated from the DMI and analyzed nutrient contents in feedstuffs (Supplemental Table S1; https://doi.org/10.3168/jds.2018-14911).

\section{Methane Measurements}

Methane production $(\mathrm{L} / \mathrm{d})$ was recorded in EW 5 and 11 for 2 subsequent 24 -h periods, each using 4 open-circuit respiration chambers as described by Derno et al. (2009) and Bielak et al. (2016). Cows were fed with respective TMR diets at 0730 and $1730 \mathrm{~h}$ and feed intake was recorded continuously by feed troughs placed on balances and summarized over $24 \mathrm{~h}$. Milking occurred at 0630 and $1630 \mathrm{~h}$. Drinking water was freely available. The concentrations of $\mathrm{CH}_{4}$ were measured at 6-min intervals throughout $23.9 \mathrm{~h}$; the data were normalized to $24 \mathrm{~h}$. The temperature and relative humidity in the chambers were $15^{\circ} \mathrm{C}$ and $65 \%$, respectively. The mean recovery rate of the chambers was $99.9 \pm 0.96 \%$. Methane production parameters were calculated as $\mathrm{CH}_{4}$ production $(\mathrm{L} / \mathrm{d}), \mathrm{CH}_{4}$ yield defined as liters of $\mathrm{CH}_{4}$ per kilogram of DMI, and $\mathrm{CH}_{4}$ intensity defined as liters of $\mathrm{CH}_{4}$ per kilogram of ECM (Table 2), where $\operatorname{ECM}(\mathrm{kg} / \mathrm{d})=[1.05+0.38 \times$ milk fat $(\%)+0.21 \times$ milk protein $(\%)] / 3.28 \times$ milk yield $(\mathrm{kg} / \mathrm{d})$ (Spiekers et al., 2009).

\section{Milk Sampling and Analyses}

During the $\mathrm{CH}_{4}$ measurements, aliquots of milk from the evening of the first and the morning of the second 24-h period were pooled proportionally according to milk yield at each milking $(0.25 \%$ of milk yield). Proximate milk composition was analyzed by the state control association Mecklenburg-Western Pomerania (Landeskontrollverband für Leistungs-und Qualitätsprüfung Mecklenburg-Vorpommern e.V., 
Güstrow, Germany) for milk fat and protein content using mid-infrared spectroscopy (MilkoScan FT6000 and MilkoScan FT+, Foss, Hillerød, Denmark). Aliquots of the pooled milk samples were stored at $-20^{\circ} \mathrm{C}$ until MFA analysis using GC (Firl et al., 2014) performed by the Bavarian Biomolecular Mass Spectrometry Center (Freising, Germany). Milk lipid was extracted by a 1:1 chloroform:methanol mixture and esterified with trimethylsulfonium hydroxide to form FAME. A GC-flame ionization detector instrument (Hewlett Packard 6890, Palo Alto, CA) with a 7683 autosampler was equipped with a $100 \mathrm{~m} \times 0.25 \mathrm{~mm}$ column $(\mathrm{CP}$ 7420; $0.25 \mu \mathrm{m}$ film thickness; Agilent Technologies, Böblingen, Germany; Firl et al., 2014). Identifications of peaks were made by comparison with known FAME standards. The GC analyses resulted in the separation and quantification (\% of total lipids) of 46 individual MFA. Because not all individual MFA were detected in all milk samples, we excluded those which occurred in less than $85 \%$ of the milk samples (C18:1 trans-10, $\mathrm{C} 18: 2$ trans-10,cis-12, and $\mathrm{C} 21: 0)$, which resulted in a total of 43 individual MFA (Table 3). Because SFA have been shown to be positively associated and UFA, MUFA, PUFA, C18:1 cis and trans isomers, and n-3 MFA have been shown to be negatively associated with $\mathrm{CH}_{4}$ emission (Chilliard et al., 2009; Castro-Montoya et al., 2016a; van Gastelen and Dijkstra, 2016), we were interested to know the predictive power of equations containing groups of biochemically related MFA instead of individual MFA. Thus, MFA concentrations were summed as groups of SFA, UFA, MUFA, PUFA, C18:1 cis and trans isomers, and n-3 MFA (Supplemental Table S2; https://doi.org/10.3168/jds.2018-14911) according to our previous study in which MFA were predicted by infrared spectroscopy (Engelke et al., 2018).

\section{Calculations and Statistical Analysis}

ANOVA. The dependent variables $\mathrm{CH}_{4}$ production, DMI, and ECM yield were measured on 2 consecutive days in EW 5 and 11 and were averaged per day in each EW. Data were analyzed with repeated measures ANOVA using PROC MIXED (SAS/STAT 9.3; SAS Institute Inc., Cary, NC). The model contained the fixed effects of basal ration (CS, GS), linseed supplementation (LS, L0), the interaction effect between basal ration and linseed supplementation, as well as effects of experimental blocks (1-5), periods (A or $\mathrm{B}$ ), and the order (LS in period A or B first). The covariance structure was set to be compound symmetry. Effects were considered significant at $P<0.05$ and least squares means were compared using the Tukey test with the
SLICE statement for performing a partitioned analysis of the least squares means for the interaction. Data are presented as least squares means \pm standard error if not given otherwise.

Regression Models and Validation. Correlations were calculated between $\mathrm{CH}_{4}$ production $(\mathrm{L} / \mathrm{d})$ values and concentrations of individual MFA and MFA groups using PROC CORR of SAS. Regression equations for the dependent variable $\mathrm{CH}_{4}$ production $(\mathrm{L} / \mathrm{d})$ were constructed from MFA data of each diet separately using PROC REG of SAS with the STEPWISE variable selection method. Regression models for MFA data from combined data categorized by basal diets or linseed supplementation, as well as for data from all 4 diets collectively, were also estimated. Six data sets of variables were used for the stepwise variable selection to enter in the regression equations. Data sets 1 to 3 included 43 different individual MFA, whereas data sets 4 to 6 were generated according to the MFA grouping of Engelke et al. (2018) and contained 7 groups of MFA (SFA, UFA, MUFA, and PUFA, C18:1 trans, C18:1 cis, and n-3 MFA) as summed concentrations plus the individual MFA C16:0 and C18:0 as key MFA in milk fat metabolism (Supplemental Table S2; https: //doi.org/10.3168/jds.2018-14911). Data set 1 included the 43 individual MFA only and data set 2 included 43 individual MFA and ECM data, whereas data set 3 included 43 individual MFA and DMI data. Data set 4 included the reduced data set of 7 groups of MFA and the 2 individual MFA only. Data set 5 included the same reduced data set of MFA variables as well as ECM, whereas data set 6 included the same reduced data set of MFA as well as DMI.

To have the most relevant explanatory variables in the regression equations and to avoid over-fitted regression models, we preselected candidate explanatory variables through their correlation coefficients with the dependent variable (i.e., $\mathrm{CH}_{4}$ production). For this purpose, only variables that had a significant correlation $(P<$ $0.05)$ with $\mathrm{CH}_{4}$ production were allowed to potentially enter in the models. Thereafter, the preselected variables were allowed to enter and remain in the regression equations with a significance threshold of $P \leq 0.05$ (i.e., entry and stay levels of the stepwise variable selection method). Subsequently, explanatory variables in the final regression equations derived from data set 1 and 4 were made available to potentially enter in the regression models for data sets 2 and 5 together with ECM or 3 and 6 together with DMI, respectively. In this way, ECM or DMI was used to additionally improve regression models derived from data sets 1 and 4 or could replace 1 or more of the explanatory variables in the final regression models. In the final regression models 
of each data set, multicollinearity was assessed through variation inflation factor, and explanatory variables were allowed to have a variation inflation factor $<10$, as suggested by Kaps and Lamberson (2004).

As cows were used rotationally with 2 different diets (L0 and LS) at 2 different periods, the regression equations based on data specific to basal ration and all diets included pooled data of periods (e.g., EW 5 and 11). This was possible because period did not affect $\mathrm{CH}_{4}$ production and MFA profiles. The regression equations based on data specific to linseed supplementation were not concerned with pooled data due to the experimental setup. The performance of the developed $\mathrm{CH}_{4}$ prediction equations was assessed by an internal cross-validation with the existing data set. A crossvalidation was performed by leaving 1 animal out at a time and performing a calibration with the remaining animals per model (each diet separately, basal diets, linseed supplementation or not, all diets collectively; Moraes et al., 2014). The root mean square error of

Table 3 Individual milk fatty acid (MFA) composition (\% of total lipids) of cows fed basal rations based on grass silage (GS) or corn silage (CS) with (LS) or without (L0) linseed supplementation

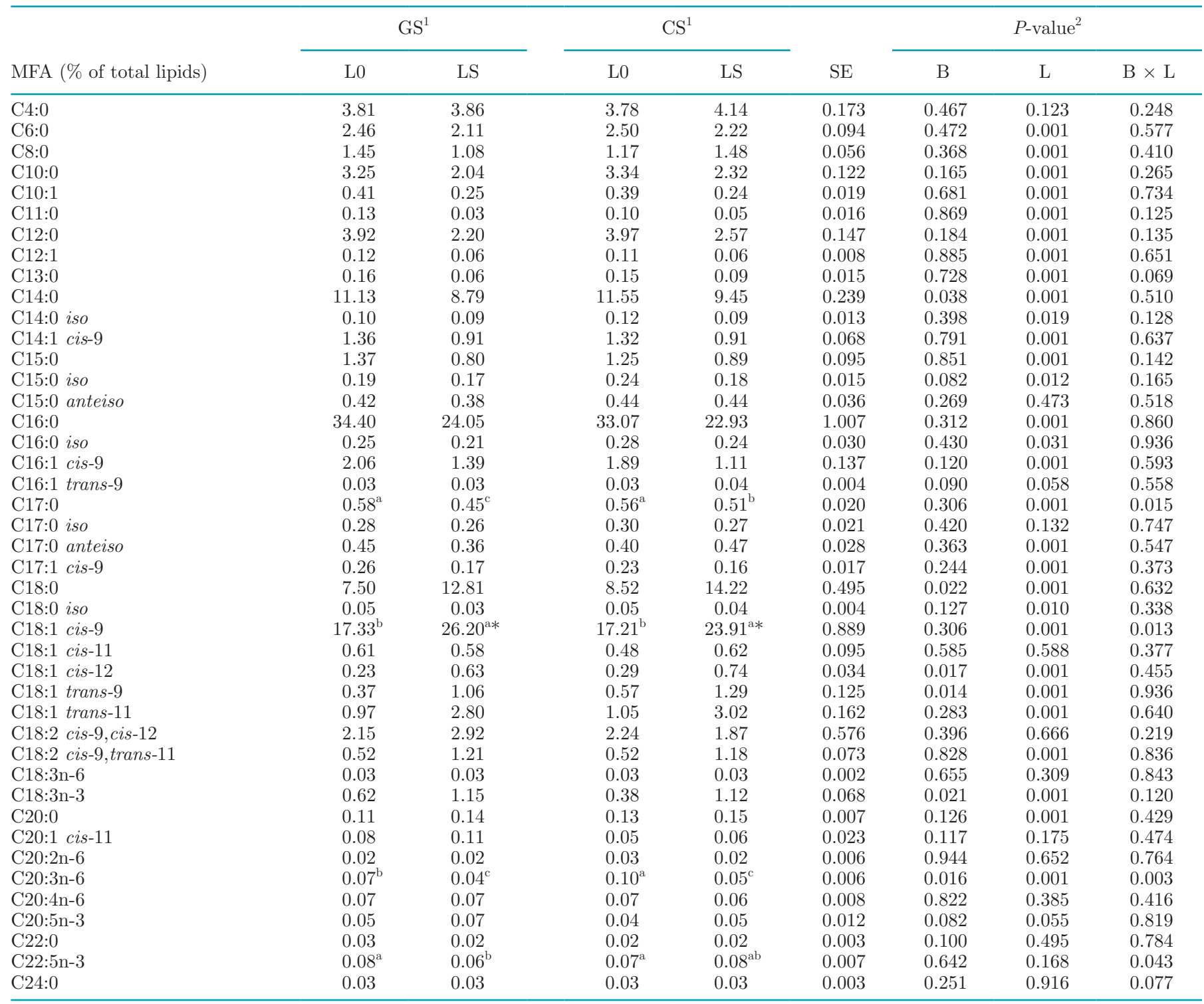

${ }^{\mathrm{a}-\mathrm{C}}$ Values within a row with differing superscripts denote $\mathrm{B} \times \mathrm{L}$ interactions $(P<0.05)$.

${ }^{1} \mathrm{LSM}$.

${ }^{2}$ ANOVA F-test for the effects of basal ration (B), linseed supplementation (L), or their interaction $(\mathrm{B} \times \mathrm{L})$.

$* P<0.10$. 
cross-validation and the cross-validation coefficient of determination $\left(\mathbf{R}_{\mathbf{C V}}{ }_{\mathbf{C V}}\right)$ were estimated (Moraes et al., 2014). In addition, we report adjusted coefficient of determination $\left(\mathbf{R}^{\mathbf{2}}{ }_{\text {Adj }}\right)$ to account for the number of variables in the final models. We further evaluated the models using the concordance correlation coefficient (CCC) as reported earlier (Dijkstra et al., 2016; van Gastelen et al., 2017). Due to the low number of observations $(n=7-10)$ and variables with multicollinearity, we refrained from reporting predictions for individual diets.

\section{RESULTS}

\section{Animal Performance and Methane Production}

Cows fed the CS rations had a higher DMI $(P=$ $0.024)$ and ECM yield $(P=0.002)$ than those fed GS rations (Table 2). Accordingly, $\mathrm{CP}$, crude fat, starch, and $\mathrm{NE}_{\mathrm{L}}$ intakes $(P<0.05)$ were higher with $\mathrm{CS}$ than with GS rations (Supplemental Table S1; https://doi .org/10.3168/jds.2018-14911). The intake of sugar was higher $(P=0.005)$ with GS rations but fiber intake was similar with both basal diets. The percentage of milk fat was higher $(P=0.035)$ with GS compared with CS feeding (Table 2). Linseed supplementation had no effect on ECM and milk fat $(P>0.3)$, but we noted a tendency toward a lower DMI $(P=0.061)$ with LS compared with L0 diets (Table 2). Feeding LS rations resulted in twice the crude fat intake $(P=0.001)$ as with L0 rations (Supplemental Table S1).
Cows fed the CS basal diets tended to have higher $\mathrm{CH}_{4}$ production compared with those cows fed the GS rations $(P=0.089$; Table 2$)$. The $\mathrm{CH}_{4}$ yield ranged from a maximum $50 \mathrm{~L} / \mathrm{kg}$ of DMI in cows fed the GS$\mathrm{L} 0$ ration to a minimum of $21 \mathrm{~L} / \mathrm{kg}$ of $\mathrm{DMI}$ with the CS-LS diet (Supplemental Table S3; https://doi.org/ 10.3168/jds.2018-14911). Basal diet had no effect on $\mathrm{CH}_{4}$ yield $(P=0.289)$, but $\mathrm{CH}_{4}$ intensity was lower $(P=0.050)$ by about $15 \%$ with $\mathrm{CS}$ than with GS rations. Furthermore, LS decreased the level of all $\mathrm{CH}_{4}$ emission parameters as compared with cows fed L0. The reduction of enteric $\mathrm{CH}_{4}$ emission levels due to LS amounted to 10 and $13 \%$ for $\mathrm{CH}_{4}$ intensity and production, respectively $(P<0.01)$. Methane yield $(\mathrm{L} / \mathrm{kg}$ of DMI) was reduced $(P=0.011)$ by approximately $6 \%$ when diets with LS were fed.

\section{MFA Composition and Correlations with Methane Production}

With CS compared with GS diets, C14:0, C18:0, C18:1 cis-12, C18:1 trans-9, C20:3n-6, and the sum of C18:1 trans MFA concentrations were higher whereas C18:3n-3 and the sum of n-3 MFA were lower (Tables 3 and $4 ; P<0.04)$. The LS diets resulted in lower concentrations of individual even-chain SFA from C6:0 to C16:0, the group of SFA $(P<0.001)$, the off-chain SFA from C11:0 to C17:0 $(P<0.001)$, and the individual MUFA C10:1, C12:1, C14:1 cis-9, C16:1 cis-9, C17:1 cis-9, as well as C18:0 iso and C20:3n-6 $(P<$ 0.05; Table 3). Most of C18 PUFA and C20:0 MFA

Table 4. Milk fatty acid (MFA) groups (\% of total lipids) as sums of concentrations of individual MFA of cows fed basal rations based on grass silage (GS) or corn silage (CS), with (LS) or without (L0) linseed supplementation

\begin{tabular}{|c|c|c|c|c|c|c|c|c|}
\hline \multirow[b]{2}{*}{ MFA ( $\%$ of total lipids) } & \multicolumn{2}{|c|}{$\mathrm{GS}^{1}$} & \multicolumn{2}{|c|}{$\mathrm{CS}^{1}$} & \multirow[b]{2}{*}{$\mathrm{SE}$} & \multicolumn{3}{|c|}{$P$-value ${ }^{2}$} \\
\hline & L0 & $\mathrm{LS}$ & L0 & LS & & B & $\mathrm{L}$ & $\mathrm{B} \times \mathrm{L}$ \\
\hline$\Sigma \mathrm{SFA}^{3}$ & 72.06 & 60.32 & 72.32 & 62.41 & 1.453 & 0.457 & 0.001 & 0.369 \\
\hline$\Sigma \mathrm{UFA}^{4}$ & 27.43 & 39.09 & 27.10 & 36.60 & 1.440 & 0.377 & 0.001 & 0.279 \\
\hline$\Sigma$ MUFA & 23.81 & 33.88 & 23.63 & 32.15 & 1.044 & 0.470 & 0.001 & 0.153 \\
\hline$\Sigma$ PUFA & 3.62 & 5.55 & 3.47 & 4.45 & 0.652 & 0.332 & 0.011 & 0.357 \\
\hline$\Sigma \mathrm{C} 18: 1 \mathrm{cis}^{5}$ & 18.17 & 27.32 & 17.99 & 25.26 & 0.948 & 0.362 & 0.001 & 0.053 \\
\hline$\Sigma \mathrm{C} 18: 1$ trans $^{6}$ & 1.33 & 3.72 & 1.62 & 4.31 & 0.193 & 0.014 & 0.001 & 0.395 \\
\hline$\Sigma \mathrm{n}-3 \mathrm{FA}^{7}$ & 0.76 & 1.29 & 0.49 & 1.25 & 0.079 & 0.031 & 0.001 & 0.128 \\
\hline$\Sigma \mathrm{n}-6 \mathrm{FA}^{8}$ & 2.34 & 3.07 & 2.47 & 2.02 & 0.585 & 0.098 & 0.001 & 0.092 \\
\hline
\end{tabular}

${ }^{1}$ LSM.

${ }^{2}$ ANOVA $F$-test for the effects of basal ration (B), linseed supplementation $(\mathrm{L})$, or their interaction $(\mathrm{B} \times \mathrm{L})$.

${ }^{3}$ Sum of C4:0, C6:0; C8:0, C10:0, C11:0, C12:0, C13:0, C14:0, C14:0 iso, C15:0, C15:0 iso, C15:0 anteiso, C16:0, C16:0 iso, C17:0, C17:0 iso, $\mathrm{C} 17: 0$ anteiso, C18:0, C18:0 iso, C20:0, C22:0, and C24:0.

${ }^{4}$ Unsaturated fatty acids (FA) represent the sum of MUFA (C10:1, C12:1, C14:1 cis-9, C16:1 cis-9, C16:1 trans-9, C17:1 cis-9, C18:1 cis-9, C18:1 cis-11, C18:1 cis-12, C18:1 trans-9, C18:1 trans-11, and C20:1 cis-11) and PUFA (C18:2 cis-9,trans-11, C18:2 cis-9,cis-12, C18:3 cis-6,cis9,cis-12, C18:3 cis-9,cis-12,cis-15, C20:2n-6, C20:3n-6, C20:4n-6, C20:5n-3, and C22:5n-3).

${ }^{5}$ Sum of $\mathrm{C} 18: 1$ cis-9, cis-11, and cis-12.

${ }^{6}$ Sum of C18:1 trans-9 and trans- 11 .

${ }^{7}$ Sum of C18:3n-3, C20:5n-3, and C22:5n-3.

${ }^{8}$ Sum of C18:2n-6, C18:3n-6, C20:2n-6, C20:3n-6, and C20:4n-6. 
concentrations were higher with LS-containing diets $(P$ $<0.05$; Table 3 ). A basal ration $\times$ linseed interaction was found for 4 of the 43 individual MFA $(P<0.05$; C17:0, C18:1 cis-9, C20:3n-6, and C22:5n-3; Table 3). The concentrations of the MFA groups UFA, MUFA, PUFA, sums of C18:1 cis or trans isomers, and the sum of n-3 FA were higher with LS compared with L0 diets $(P<0.01$; Table 4$)$.

For combined data of all diets collectively, positive correlations were found between $\mathrm{CH}_{4}$ production and concentrations of selected individual SFA, the sum of all SFA, as well as C18:3n-6 $(P \leq 0.05$; Figure 1 and Supplemental Table S4; https://doi.org/10.3168/jds .2018-14911). We observed negative correlations between $\mathrm{CH}_{4}$ production and the levels of individual MFA of $\mathrm{C} 15: 0$ iso, $\mathrm{C} 17: 1$ cis-9, $\mathrm{C} 18: 1$ cis-9, C18:1 cis-11, $\mathrm{C} 18: 1$ cis-12, C18:1 trans-9, C18:3n-3, and $\mathrm{C} 22: 0$ and groups of UFA, MUFA, C18:1 cis and trans isomers, and n-3 MFA $(P \leq 0.05)$. Correlations of $\mathrm{CH}_{4}$ production with the levels of individual MFA differed for data of the various pooled diets (Figure 1 and Supplemental Table S4). For example, correlations between C10:0 and $\mathrm{CH}_{4}$ production ranged from $0.07(P=0.76)$ for the L0 diets to $0.63(P=0.006)$ for the LS diets, and for $\mathrm{C} 18: 3 \mathrm{n}-3$ from $-0.17(P=0.509)$ for the GS diets to $-0.70(P=0.002)$ for the LS diets; correlations for C24:0 ranged from $0.14(P=0.605)$ for the LS diets to $0.83(P=0.001)$ for the CS diets.

\section{Methane Prediction Models Using the Complete Set of MFA Variables}

The prediction of $\mathrm{CH}_{4}$ production based on data sets 1 to 3 resulted in coefficients of determination of the models $\left(\mathbf{R}^{2}{ }_{\text {Model }}\right)$ between 0.36 and $0.91(P<0.01)$, $\mathrm{R}_{\text {Adj }}^{2}$ between 0.32 and $0.89, \mathrm{R}_{\mathrm{CV}}^{2}$ between 0.47 and 0.92 , and root mean square error between 38.78 and 97.41, whereas CCC was between 0.53 and 0.95 (Table 5). The $\mathrm{R}_{\text {Adj }}^{2}$ values were slightly but systematically lower than that for $\mathrm{R}_{\text {Model }}^{2}$. The additional inclusion of ECM (data set 2) resulted in higher $R_{\text {Model }}^{2}$ values, ranging from 0.61 to 0.91 , and $\mathrm{R}_{\mathrm{CV}}^{2}$, from 0.71 to 0.92 , as compared with data set 1 . Nevertheless, for all diets combined, the $R_{\text {Model }}^{2}(0.69)$ and $R_{C V}^{2}$ (0.74) of the equations for data set 2 were lower compared with that of data set $1\left(\mathrm{R}_{\text {Model }}^{2}=0.81\right.$ and $\left.\mathrm{R}_{\mathrm{CV}}^{2}=0.85\right)$. The inclusion of DMI (data set 3) instead of ECM (data set 2) resulted in comparable prediction values, with an $\mathrm{R}^{2}$ Model range from 0.62 to 0.91 and $\mathrm{R}_{\mathrm{CV}}^{2}$ from 0.70 to 0.92 (Table 5). With the exception of the GS diets, the $\mathrm{R}_{\mathrm{CV}}^{2}$ and $\mathrm{CCC}$ values based on data sets 1 to 3 were at least 0.74 and 0.82 , respectively, or higher. The $\mathrm{R}_{\mathrm{CV}}^{2}$ based on GS diets was always lower compared with that of CS diets
Fatty acid

C4:0

C $6: 0$

C10:0

C10:1

C11:0

C12:0

C12:1

C13:0

C14:0

C14:0 iso

C14:1 cis-9

C15:0

C15:0 iso

C15:0 anteiso

C16:0

C16:0 iso

C16:1 cis-9

C16:1 trans-9

C17:0

C17:0 iso

C17:0 anteiso

C17:1 cis-9

C18:0

C18:0 iso

C18:1 cis-9

C18:1 cis-11

C18:1 cis-12

C18:1 trans-9

C18:1 trans-11

C18:2 cis-9,cis-12

C18:2 cis-9,trans-11

C18:3n-6

C18:3n-3

C20:0

C20:1 cis-11

C20:2n-6

C2 $0: 3 n-6$

C20:4n-6

C20:5n-3

C22:0

C22:5n-3

C $24: 0$

$\sum$ SFA

$\sum$ UFA

$\sum$ MUFA

$\sum$ PUFA

$\sum \mathrm{C} 18: 1 \mathrm{cis}$

$\sum$ C18:1 trans

$\sum \mathrm{n}-3 \mathrm{FA}$
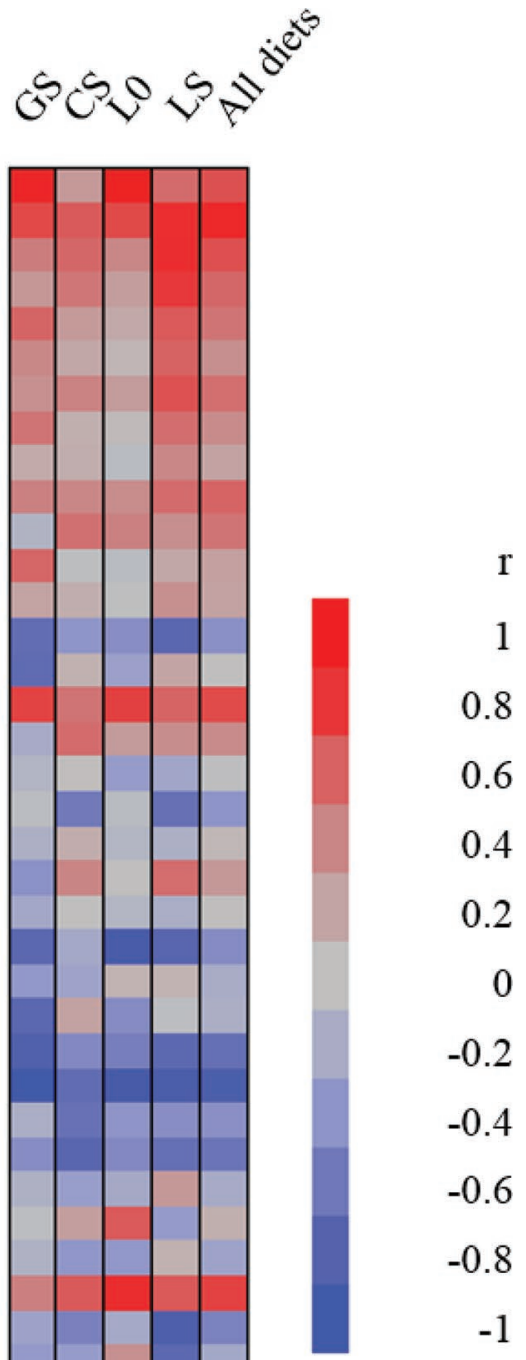

Figure 1. Heatmap of correlations between individual and groups of milk fatty acids ( $\%$ of total lipids) and methane production ( $\mathrm{L} / \mathrm{d}$ ) calculated from data of the combined basal diets [grass silage (GS), corn silage (CS)], each basal diet with (L0) or without (LS) linseed supplementation, and all diets collectively. 
Table 5. Summary of quality parameters and validation results of the multiple regression equations predicting methane production $\left(\mathrm{CH}_{4}, \mathrm{~L} / \mathrm{d}\right)$ using the complete data set of 43 milk fatty acid (MFA) variable (data sets 1-3), or a reduced number of MFA variables and groups of MFA (data sets 4-6)

\begin{tabular}{|c|c|c|c|c|c|c|c|}
\hline Pooled diets & $\mathrm{N}$ & $\mathrm{R}_{\text {Model }}^{2}$ & $P_{\text {Model }}$ & $\mathrm{R}_{\text {Adj }}^{2}$ & $\mathrm{CCC}$ & RMSE & $\mathrm{R}_{\mathrm{CV}}^{2}$ \\
\hline \multicolumn{8}{|l|}{ Data set 1} \\
\hline GS & 17 & 0.36 & 0.011 & 0.32 & 0.53 & 97.41 & 0.47 \\
\hline CS & 20 & 0.86 & 0.001 & 0.84 & 0.93 & 45.54 & 0.89 \\
\hline L0 & 20 & 0.85 & 0.001 & 0.83 & 0.92 & 60.74 & 0.87 \\
\hline LS & 17 & 0.78 & 0.001 & 0.75 & 0.88 & 41.77 & 0.84 \\
\hline All diets & 37 & 0.81 & 0.001 & 0.78 & 0.90 & 56.38 & 0.85 \\
\hline \multicolumn{8}{|l|}{ Data set 2} \\
\hline GS & 17 & 0.61 & 0.001 & 0.58 & 0.75 & 77.84 & 0.71 \\
\hline CS & 20 & 0.91 & 0.001 & 0.89 & 0.95 & 41.79 & 0.91 \\
\hline L0 & 20 & 0.91 & 0.001 & 0.89 & 0.95 & 48.25 & 0.92 \\
\hline LS & 17 & 0.78 & 0.001 & 0.75 & 0.88 & 41.77 & 0.84 \\
\hline All diets & 37 & 0.69 & 0.001 & 0.67 & 0.82 & 75.28 & 0.74 \\
\hline \multicolumn{8}{|l|}{ Data set 3} \\
\hline GS & 17 & 0.62 & 0.001 & 0.60 & 0.77 & 79.74 & 0.70 \\
\hline CS & 20 & 0.91 & 0.001 & 0.89 & 0.95 & 39.55 & 0.92 \\
\hline L0 & 20 & 0.90 & 0.001 & 0.88 & 0.95 & 50.25 & 0.91 \\
\hline LS & 17 & 0.81 & 0.001 & 0.79 & 0.90 & 38.78 & 0.87 \\
\hline All diets & 37 & 0.74 & 0.001 & 0.73 & 0.85 & 66.86 & 0.80 \\
\hline \multicolumn{8}{|l|}{ Data set 4} \\
\hline GS & 17 & 0.26 & 0.035 & 0.21 & 0.42 & 106.50 & 0.31 \\
\hline CS & 20 & 0.42 & 0.002 & 0.39 & 0.59 & 83.24 & 0.56 \\
\hline L0 & 20 & 0.57 & 0.001 & 0.52 & 0.72 & 93.39 & 0.67 \\
\hline LS & 17 & 0.49 & 0.002 & 0.46 & 0.66 & 60.61 & 0.62 \\
\hline All diets & 37 & 0.30 & 0.001 & 0.28 & 0.46 & 93.75 & 0.48 \\
\hline \multicolumn{8}{|l|}{ Data set 5} \\
\hline GS & 17 & 0.61 & 0.001 & 0.58 & 0.75 & 77.67 & 0.71 \\
\hline CS & 20 & 0.74 & 0.001 & 0.71 & 0.85 & 61.84 & 0.79 \\
\hline L0 & 20 & 0.70 & 0.001 & 0.69 & 0.82 & 74.30 & 0.80 \\
\hline LS & 17 & 0.49 & 0.002 & 0.46 & 0.66 & 60.61 & 0.62 \\
\hline All diets & 37 & 0.69 & 0.001 & 0.67 & 0.82 & 64.57 & 0.80 \\
\hline \multicolumn{8}{|l|}{ Data set 6} \\
\hline GS & 17 & 0.62 & 0.001 & 0.60 & 0.77 & 79.56 & 0.70 \\
\hline CS & 20 & 0.80 & 0.001 & 0.78 & 0.89 & 54.31 & 0.84 \\
\hline L0 & 20 & 0.73 & 0.001 & 0.72 & 0.85 & 73.34 & 0.80 \\
\hline LS & 17 & 0.56 & 0.001 & 0.53 & 0.72 & 57.01 & 0.68 \\
\hline All diets & 37 & 0.73 & 0.001 & 0.71 & 0.84 & 62.45 & 0.81 \\
\hline
\end{tabular}

${ }^{1}$ Each row summarizes validation results for a regression equation specific to data of diets based on combinations of basal ration [grass silage (GS), corn silage (CS)] and linseed supplementation [without (L0), with (LS)] or all diets collectively. Data set 1 included MFA only. Data sets 2 and 3 included individual MFA and ECM or DMI, respectively, as independent variables. Data set 4 included MFA variables (reduced number of variables) only, whereas data sets 5 and 6 additionally included ECM or DMI, respectively. The $\mathrm{R}_{\text {Model }}^{2}$ and $P_{\text {Model }}$ values, the adjusted $\mathrm{R}_{\text {Adj }}^{2}$, the concordance correlation coefficient $(\mathrm{CCC})$ of the model, the root mean square error (RMSE) of cross-validation as well as the cross-validation coefficient of determination $\left(\mathrm{R}_{\mathrm{CV}}^{2}\right)$ are given

$\left(\mathrm{R}_{\mathrm{CV}}^{2}\right.$ from 0.47 to 0.71 vs. 0.89 to 0.92$)$. We found no discernible pattern of predictive MFA as explanatory variables in the prediction equations. However, C18:1 cis-9 and C24:0 appeared more often in the prediction equations than others (Supplemental Table S5; https:/ /doi.org/10.3168/jds.2018-14911).

\section{Methane Prediction Models Using a Reduced Number of MFA Variables}

Three data sets (data sets 4 to 6 ) comprising the concentrations of a reduced number of MFA and biochemically related groups of summed MFA (Supplemental Table S2; https://doi.org/10.3168/jds.2018-14911) were used to develop multiple regression equations. Using data set 4 , prediction of $\mathrm{CH}_{4}$ production resulted in $\mathrm{R}_{\text {Model }}^{2}$ between 0.26 and $0.57, \mathrm{R}_{\text {Adj }}^{2}$ between 0.21 and 0.52 , CCC between 0.42 and 0.72 , and a $\mathrm{R}_{\mathrm{CV}}^{2}$ between 0.31 and 0.67 (Table 5). The additional inclusion of ECM (data set 5) or DMI (data set 6) increased the $\mathrm{R}_{\text {Model }}^{2}$ and $\mathrm{R}_{\mathrm{CV}}^{2}$ values, respectively, compared with data set 4 . The $R_{\text {Adj }}^{2}$ values were similar to $R_{\text {Model }}^{2}$ but systematically lower. Models for CS diets always resulted in a higher prediction $\left(\mathrm{R}_{\mathrm{CV}}^{2}\right.$ from 0.56 to 0.84$)$ and higher CCC values (from 0.59 to 0.89 ) compared with GS diets. Similarly, models of data from L0 diets $\left(\mathrm{R}_{\mathrm{CV}}^{2}\right.$ from 0.67 to 0.80 , CCC from 0.72 to 0.85$)$ gave higher predictions as compared with LS diets (Table 5). 
However, for the LS diets, the inclusion of ECM (data set 5) did not improve the model. Predictions based on data from all 4 diets collectively including ECM as an explanatory variable in the model enhanced the predictive power by $130 \%\left(\mathrm{R}_{\text {Model }}^{2}=0.69\right)$ and $69 \%\left(\mathrm{R}_{\mathrm{CV}}^{2}\right.$ $=0.80)$ compared with data set $4\left(\mathrm{R}_{\text {Model }}^{2}=0.30\right.$ and $\left.\mathrm{R}_{\mathrm{CV}}^{2}=0.48\right)$. The dominant predictive MFA variable in the regression equations of data set 4 to 6 was the MFA group MUFA (Supplemental Table S5; https://doi.org/ 10.3168/jds.2018-14911).

\section{DISCUSSION}

\section{Animal Performance, Methane Production Parameters, and MFA Composition}

The CS diets resulted in a higher DMI and ECM yield than the GS diets, which was comparable to what was reported previously for diets with higher proportions of corn silage than grass silage (Kliem et al., 2008; Sterk et al., 2011; Livingstone et al., 2015). In contrast to earlier studies, the type of the basal ration did not affect $\mathrm{CH}_{4}$ yield (L/kg of DMI) of cows (Beauchemin et al., 2008; Hart et al., 2015; van Gastelen et al., 2015). This was likely due to similar crude fiber, ADF, and NDF intakes with grass- and corn silage-based diets. To make the diets isoenergetic, wheat and barley were added to the GS-L0 diet, and this added starch, diluted the fiber content, and aligned the fiber intake of the 2 basal diets. Furthermore, effects of starch and sugar in the GS-L0 diets might have reduced $\mathrm{CH}_{4}$ production, which otherwise was expected to be higher with diets containing higher proportions of grass silage (van Gastelen et al., 2015). Although the NDF/DMI value was still higher in GS-based diets, the DMI and energy intake of cows fed GS diets was, on average, $3 \mathrm{~kg}$ and $17 \% \mathrm{MJ}$ of $\mathrm{NE}_{\mathrm{L}}$ less per day, respectively, as compared with the CS-based diets. This is a limitation of our study and possibly affected the width of range of $\mathrm{CH}_{4}$ production. Methane production $(\mathrm{L} / \mathrm{d})$ tended to be higher with CS compared with GS diets due to the higher DMI, which is known to explain 52 to $64 \%$ of $\mathrm{CH}_{4}$ production (Knapp et al., 2014). In contrast, $\mathrm{CH}_{4}$ intensity tended to be lower in the CS than in the GS group due to higher ECM yield, which illustrates the importance of a high milk performance to mitigate $\mathrm{CH}_{4}$ intensity (Yan et al., 2010; Zehetmeier et al., 2012; Gerber et al., 2013).

We observed only few differences in MFA concentrations between basal rations, although others reported more diverse MFA patterns with different silage types (Kliem et al., 2008; Livingstone et al., 2015; van Gastelen et al., 2015). For example, diets with different proportions of grass and corn silage differed in the MFA concentrations of C18:1 isomers, total CLA, C18: 2n-6, and C18:3n-3 (Kliem et al., 2008; van Gastelen et al., 2015). The small differences in concentrations of only a few MFA among basal diets found here were due to similar crude fiber, ADF, and NDF intakes with the basal diets, as discussed above. This can limit the range of MFA concentrations, and thus may affect $\mathrm{CH}_{4}$ prediction.

In the present study, dietary supplementation of linseed decreased the level of all $\mathrm{CH}_{4}$ emission parameters by 6,10 and $13 \%$ for $\mathrm{CH}_{4}$ yield, intensity, and production, although the reductive effects were greater with CS diets, as was observed earlier (Benchaar et al., 2015; Martin et al., 2016). Others found reductions in $\mathrm{CH}_{4}$ yield between 8 and $20 \%$ by feeding various diets supplemented with extruded linseed ( 5 to $10 \%$ of dietary DM) or linseed oil (4\% of dietary DM; Benchaar et al., 2015; Martin et al., 2016; Bayat et al., 2018). A $10 \mathrm{~g} / \mathrm{kg}$ of DM increase in dietary fat resulted in a lower $\mathrm{CH}_{4}$ yield by $1 \mathrm{~g} / \mathrm{kg}$ of DMI in cattle (Grainger and Beauchemin, 2011). An increase of $1 \%$ in dietary lipid content led to a 4 to $5 \%$ reduction of $\mathrm{CH}_{4}$ production (Clark, 2013). In our study, the LS diets contained $28 \mathrm{~g} / \mathrm{kg}$ of DM more crude fat than the L0 diets, which corresponds to a lower $\mathrm{CH}_{4}$ yield by $2.8 \mathrm{~g} / \mathrm{kg}$ of DM, or 12 to $15 \%$. The actual reduction of $\mathrm{CH}_{4}$ yield by LS supplementation of GS and CS diets was 0.7 and 2.1 $\mathrm{g} / \mathrm{kg}$ of DM or 2.7 and $9.4 \%$, respectively. Thus, in our study, the linseed supplementation reduced $\mathrm{CH}_{4}$ yield less than predicted by Grainger and Beauchemin (2011) or Clark (2013), but the reduction was larger with the corn silage-based diet. The lesser mitigation observed in our study compared with Grainger and Beauchemin (2011) might be due to the fact that we did not add linseed oil but linseeds to the diets. This might reduce or slow down the release of linseed oil in the rumen and is thus less suppressive to methanogens. As argued by Benchaar et al. (2015), the type of basal diet might influence the effect of linseed oil on $\mathrm{CH}_{4}$ mitigation. For example, Chung et al. (2011) observed a mitigation effect of linseed only in combination with feeding barley silage (33\% of $\mathrm{CH}_{4}$ yield) but not with grass hay. This is similar to what was found in our study, which might be due to the opposite effect of linseed and grass, grass hay, or grass silage on $\mathrm{CH}_{4}$ production.

Linseed supplementation tended to reduce DMI. Others observed no decrease of DMI when linseed supplementation was moderate $(\leq 60 \mathrm{~g}$ of fat $/ \mathrm{kg}$ of DM) as compared with a control diet (Ferlay et al., 2013 Kliem et al., 2017; Meignan et al., 2017). In the present study, the higher concentrate content in L0 diets was used to compensate for the higher energy density of linseed, 
which might have led to a slightly higher DMI because concentrate is known as a favored feedstuff of cows when forage is provided ad libitum (Reynolds, 2006; Allen, 2014). The LS-supplemented diets contained twice the amount of fat than the nonsupplemented diets, which affected the concentrations of the majority of MFA. Almost all SFA were decreased with linseed supplementation through the direct inhibitory effect of long-chain SFA and UFA on fiber digestibility and de novo synthesis of MFA (Maia et al., 2007; Glasser et al., 2008; Shingfield et al., 2013). In contrast, C4:0 in milk fat was not affected by LS-containing diets. Effects of linseed on C4:0 concentrations are inconsistent in the literature (Ferlay et al., 2013; van Lingen et al., 2014; Kliem et al., 2017). Concentrations of off- and branched-chain MFA, which are derived from microbial synthesis (Vlaeminck et al., 2015), decreased when diets were supplemented by linseed. Lower levels of off- and branched-chain MFA are presumably related to the toxic effects of dietary PUFA on rumen microbiota (Enjalbert et al., 2017). The intake of increased levels of C18:3n-3 MFA with LS-supplemented diets increased the proportion of C18 MFA in milk fat due to biohydrogenation (Buccioni et al., 2012; Meignan et al., 2017). Diets containing linseed decreased SFA and increased UFA, trans MFA, n-3 MFA, and C18:0 (Chilliard et al., 2009; Ferlay et al., 2013; Meignan et al., 2017); the magnitude of changes in MFA pattern depended on the amount and form of linseed supply (Chilliard et al., 2009; Shingfield et al., 2013). Ferlay et al. (2013) showed that the C18:1 cis/trans isomer profile was specific for the forage type. This was similar to our study, where the C18:1 trans isomers were forage typedependent, whereas the addition of linseed increased both $\mathrm{C} 18: 1$ cis and trans isomers.

\section{Diet Effects on the Relationship Between MFA and $\mathrm{CH}_{4}$ Production and $\mathrm{CH}_{4}$ Prediction}

Each diet produces a characteristic MFA pattern (Kliem et al., 2008; Ferlay et al., 2013; Shingfield et al., 2013). We compared the correlations of individual MFA with $\mathrm{CH}_{4}$ production among pooled diets (GS, CS, L0, LS, all diets) and found-depending on the dietary group - positive, negative, or no correlations. When using MFA data of all 4 diets collectively, we observed moderate correlations between $\mathrm{CH}_{4}$ production and individual MFA (maximum $\mathrm{r}=0.52$ vs. -0.62 ). In a meta-analysis combining data from studies with a variety of different diets, weak to moderate correlations between $\mathrm{CH}_{4}$ yield and intensity and MFA were detected (maximum $\mathrm{r}=0.36$ vs. -0.56 ; van Lingen et al., 2014). This suggests that direction and strength of correlations between individual MFA and $\mathrm{CH}_{4}$ emission parameters can be explained by the interaction of different dietary constituents on MFA patterns and $\mathrm{CH}_{4}$ production. Thus, when MFA data derived from different diets were combined to determine the overall relationship between individual MFA and $\mathrm{CH}_{4}$ production, the average correlation was weak to moderate. In general, our results confirm earlier observations that correlations between $\mathrm{CH}_{4}$ production and some of the de novo-synthesized MFA and groups of SFA are positive, but negative for C18:1 cis isomers, UFA, MUFA, and n-3 FA (Chilliard et al., 2009; Mohammed et al., 2011; van Lingen et al., 2014).

When comparing $\mathrm{CH}_{4}$ prediction among the tested diets, the coefficients of determination were lower for GS diets compared with CS diets. The effect of basal diet (GS and CS) on the $\mathrm{CH}_{4}$ prediction potential was likely limited in our study because of few differences in MFA concentrations between basal rations, as discussed above. The prediction equations based on MFA data of diets containing linseed (LS vs. L0) produced 15 to $23 \%$ lower $\mathrm{R}_{\mathrm{CV}}^{2}$ values compared with data from diets with no linseed, irrespective of the data set used. That linseed supplementation deteriorates $\mathrm{CH}_{4}$ prediction confirms earlier observations (Williams et al., 2014; Dijkstra et al., 2016; Rico et al., 2016). Williams et al. (2014) concluded that the $\mathrm{CH}_{4}$ prediction model by Chilliard et al. (2009) is a result of linseed oil supplementation and cannot accurately predict $\mathrm{CH}_{4}$ when cows are fed other diets. Furthermore, Dijkstra et al. (2016) adopted the $\mathrm{CH}_{4}$ prediction equations by van Lingen et al. (2014) and concluded that MFA profile and $\mathrm{CH}_{4}$ yield of cows fed grass- or grass silage-based diets differ from those fed other diet types, especially for diets containing fat additives. In this context, Rico et al. (2016) pointed out that interaction effects of basal rations and linseed supplementation may influence prediction equations. Thus, as outlined above, we concluded that the high intake of n-3 FA affected interrelated biochemical pathways on several tissue and metabolic levels but in opposite directions for $\mathrm{CH}_{4}$ production and MFA concentrations. Furthermore, we cannot exclude that tissue FA synthesis, desaturation, and elongation, which are unrelated to changes in rumen fermentation and thus $\mathrm{CH}_{4}$ production, play a more dominant role when higher amounts of n-3 FA were fed.

\section{Methane Prediction Models Using Full and Reduced Data Sets for MFA Variables}

Our second objective was to compare $\mathrm{CH}_{4}$ prediction models based on differently sized and composed data sets of MFA. Therefore, we compared $\mathrm{CH}_{4}$ prediction 
equations based on all 43 quantified MFA (full set; data sets 1 to 3 ) to equations constructed from a reduced number of MFA variables containing groups of biochemically related MFA (data sets 4 to 6 ). In previous studies it has been shown that the selected MFA groups as well as the individual MFA are positively (SFA, C16:0) or negatively (UFA, MUFA, PUFA, n-3 MFA, C18:0) associated with $\mathrm{CH}_{4}$ emission (Castro-Montoya et al., 2016a; van Gastelen and Dijkstra, 2016). Models based on all 43 MFA showed a better prediction than those based on the reduced number of MFA group variables. In other studies, the prediction for $\mathrm{CH}_{4}$ emission based on 24 to $83 \mathrm{MFA}$ variables ranged between coefficients of determination of 0.47 and 0.95 (Chilliard et al., 2009; van Lingen et al., 2014; Rico et al., 2016), which is in the same range as with our equations, except for the GS diets in data sets 1 and 4 .

The MFA entered in the equations as explanatory variables using data sets 1 to 3 differed within the data sets. Explanatory individual MFA frequently (4 to 7 times) occurring in our prediction equations were also found in other $\mathrm{CH}_{4}$ prediction equations [i.e., C17:1 cis-9 (Mohammed et al., 2011; Castro-Montoya et al., 2016b; Rico et al., 2016), C18:1 cis-9 (van Lingen et al., 2014), and C24:0 (van Gastelen et al., 2017)]. van Gastelen and Dijkstra (2016) pointed out that only C17:1 cis-9 and C18:1 cis-11 appeared in several published equations, but in our study $\mathrm{C} 18: 1$ cis-11 did not play a major role. When ECM or DMI were additionally included, C18:1 cis-11 was not considered. The explanatory MFA variable C17:1 cis-9 is derived from rumen microbial membrane lipids or from propionate (Vlaeminck et al., 2006) and is negatively associated with $\mathrm{CH}_{4}$ production $(\mathrm{g} / \mathrm{d}$; Mohammed et al., 2011; Castro-Montoya et al., 2016b; Rico et al., 2016). In contrast, C18:1 cis-9 is derived directly from plant feed or is a desaturation product of $\mathrm{C} 18: 0$, one of the major products when diets rich in forage and plant oils are fed (Alves et al., 2013; Meignan et al., 2017). Long-chain MFA ( $\geq$ C20) are scarcely reported because they seem to be less frequently analyzed in $\mathrm{CH}_{4}$-prediction studies (Dijkstra et al., 2011; van Lingen et al., 2014). Only a few publications reported long-chain MFA (C20:1 cis9, C20:1 cis-11, C20:4n-3, C22:0, C22:6n-3, C24:0) as explanatory variables for $\mathrm{CH}_{4}$ prediction (Mohammed et al., 2011; Castro-Montoya et al., 2016b; van Gastelen et al., 2017). Models based on a reduced number of MFA variables using concentration sums of groups of biochemically related MFA showed MUFA as dominating explanatory variable. The group of MUFA includes biohydrogenation intermediates and was therefore reported to be negatively associated with $\mathrm{CH}_{4}$ production
(Mohammed et al., 2011; Castro-Montoya et al., 2016a; Vanrobays et al., 2016). Although SFA could not be identified as important explanatory variable for $\mathrm{CH}_{4}$ production in our study, Weill et al. (2009) proposed SFA $<\mathrm{C} 16$ as predictors for $\mathrm{CH}_{4}$ intensity.

\section{Additional Inclusion of ECM and DMI in Prediction Models}

Recently, it was suggested that the combination of MFA data sets with other $\mathrm{CH}_{4}$ proxies could improve $\mathrm{CH}_{4}$ prediction (van Gastelen and Dijkstra, 2016; Negussie et al., 2017). Rico et al. (2016) predicted $\mathrm{CH}_{4}$ production $(\mathrm{g} / \mathrm{d})$ for cows with models including diet components, MFA, and DMI as variables in the data sets, but it turned out that in the best-fit model diet components as explanatory variables did not play a role; this indicates that the inclusion of DMI or ECM could be more meaningful as explanatory variables for the prediction models than dietary composition. The best equation reported by Chilliard et al. (2009) also included forage DMI as a parameter, indicating its potential importance. Thus, our third objective was to test the effect of additional inclusion of ECM and DMI. Dry matter intake is the major determinant for $\mathrm{CH}_{4}$ production (Knapp et al., 2014) and ECM can reflect DMI (Hristov et al., 2013). Inclusion of ECM or DMI improved $\mathrm{CH}_{4}$-prediction equations, resulting in an increase of the $\mathrm{R}_{\mathrm{CV}}^{2}$ by approximately $30 \%$ when based on pooled data from all diets. This was only true for the data set 5 and 6 with a reduced number of MFA variables, showing that $\mathrm{CH}_{4}$ prediction by the complete set of $43 \mathrm{MFA}$ variables could explain more variability of $\mathrm{CH}_{4}$ production than DMI or ECM. van Gastelen et al. (2017) reported improved prediction of $\mathrm{CH}_{4}$ production by $29 \%$ when using equations containing MFA plus volatile and nonvolatile metabolites of milk as compared with equations based on 42 MFA variables alone, indicating that accuracy of prediction can be gained from inclusion of $\mathrm{CH}_{4}$ proxies other than only MFA as explanatory variables. Interestingly, with MFA data based on the GS diet with addition of ECM (data sets 2 and 5) or DMI (data sets 3 and 6) as a variable excluded MFA as explanatory variable from the equation. This might explain why the predictions for GS diets resulted in the lowest-quality parameters, because GS diets combine feedstuffs and nutrients with opposite effects on $\mathrm{CH}_{4}$ production (Maia et al., 2007; Shingfield et al., 2013; Castro-Montoya et al., 2016a). In contrast, based on data of the LS diets, inclusion of ECM (data sets 2 and 5) did not improve the prediction as compared with predictions with data sets 1 and 4 , 
respectively, containing MFA variables only, suggesting a dominant effect of linseed (i.e., n-3 MFA) on the MFA pattern and thus $\mathrm{CH}_{4}$ prediction.

\section{CONCLUSIONS}

Our study shows that the effect of the 2 basal diets containing either a large proportion of grass silage or corn silage on $\mathrm{CH}_{4}$ production and MFA profile was small due to only moderate intake differences in crude fiber, $\mathrm{ADF}$, and NDF, nutrients known to have a large effect on both $\mathrm{CH}_{4}$ production and MFA profile. However, with CS diets DMI was higher and resulted in a tendency for higher $\mathrm{CH}_{4}$ production. In contrast, the supplementation of the basal diets with linseed strongly reduced $\mathrm{CH}_{4}$ emission parameters, and modified the MFA profile considerably. The developed $\mathrm{CH}_{4}$ prediction models for dairy cows based on a data set of 43 individual MFA provided good prediction $\left(\mathrm{R}_{\text {Adj }}^{2} 0.32\right.$ to $0.89 ; \mathrm{R}_{\mathrm{CV}}^{2} 0.47$ to 0.92 ), which was reduced by 10 to $15 \%$ for models based on a reduced data set with 9 MFA parameters (biochemically related MFA groups and C16:0 and C18:0 MFA). Prediction of $\mathrm{CH}_{4}$ production based on a reduced data set can be improved when ECM or DMI are added as variables, indicating a gain of prediction accuracy when combining $\mathrm{CH}_{4}$ proxies. In this study, prediction equations based on GS diets resulted in the lowest prediction accuracy, which might be due to fiber and starch as TMR ingredients in our GS diets with opposite effects on methane production. Prediction equations based on diets with linseed supplements had a lower prediction accuracy compared with equations based on data from diets without linseed. Therefore, caution is needed when prediction equations are derived from data sets including fat-supplemented diets or when diet-specific prediction equations are applied to cows fed nonmatching diets.

\section{ACKNOWLEDGMENTS}

The authors express their gratitude to K.-D. Witt, B. Stabenow, D. Oswald, T. Lenke, R. Gaeth, A. Schulz, and K. Pilz, staff members at the EAR and the Tiertechnikum of the Leibniz Institute for Farm Animal Biology (FBN), for preparation of TMR, feeding, and animal care as well as assistance with sample collection and indirect calorimetry measurements. The assistance of F. Schultz (RinderAllianz GmbH, Woldegk, Germany) in the selection of cows is gratefully acknowledged. We thank DANONE GmbH, Haar, Germany, for providing milk composition data and V. Krüger and B. Göschl of DANONE GmbH for their involvement and fruitful discussions. This work was part of the project "Innovation potential to reduce greenhouse gas emissions in the dairy supply chain" (INNO MilCH4) and was supported by funds of the Federal Ministry of Food, and Agriculture (BMEL, Berlin) based on a decision of the Parliament of the Federal Republic of Germany via the Federal Office for Agriculture and Food (BLE, Bonn) under the innovation support programme (grant no. 2817501011). Publication of this article was funded by the Open Access Fund of the Leibniz Institute for Farm Animal Biology (FBN), Dummerstorf, Germany.

\section{REFERENCES}

Allen, M. S. 2014. Drives and limits to feed intake in ruminants. Anim. Prod. Sci. 54:1513-1524.

Alves, S. P., J. Santos-Silva, A. R. J. Cabrita, A. J. M. Fonseca, and R. J. B. Bessa. 2013. Detailed dimethylacetal and fatty acid composition of rumen content from lambs fed lucerne or concentrate supplemented with soybean oil. PLoS One 8:e58386.

Angulo, J., B. Hiller, M. Olivera, L. Mahecha, D. Dannenberger, G. Nuernberg, B. Losand, and K. Nuernberg. 2012. Dietary fatty acid intervention of lactating cows simultaneously affects lipid profiles of meat and milk. J. Sci. Food Agric. 92:2968-2974.

Bayat, A. R., I. Tapio, J. Vilkki, K. J. Shingfield, and H. Leskinen. 2018. Plant oil supplements reduce methane emissions and improve milk fatty acid composition in dairy cows fed grass silage-based diets without affecting milk yield. J. Dairy Sci. 101:1136-1151.

Beauchemin, K. A., M. Kreuzer, F. O'Mara, and T. A. McAllister. 2008. Nutritional management for enteric methane abatement: A review. Aust. J. Exp. Agric. 48:21-27.

Benchaar, C., F. Hassanat, R. Martineau, and R. Gervais. 2015. Linseed oil supplementation to dairy cows fed diets based on red clover silage or corn silage: Effects on methane production, rumen fermentation, nutrient digestibility, $\mathrm{N}$ balance, and milk production. J. Dairy Sci. 98:7993-8008.

Bielak, A., M. Derno, A. Tuchscherer, H. M. Hammon, A. Susenbeth, and B. Kuhla. 2016. Body fat mobilization in early lactation influences methane production of dairy cows. Sci. Rep. 6:28135.

Buccioni, A., M. Decandia, S. Minieri, G. Molle, and A. Cabiddu. 2012. Lipid metabolism in the rumen: New insights on lipolysis and biohydrogenation with an emphasis on the role of endogenous plant factors. Anim. Feed Sci. Technol. 174:1-25.

Castro-Montoya, J. M., S. De Campeneere, B. De Baets, and V. Fievez. 2016a. The potential of milk fatty acids as biomarkers for methane emissions in dairy cows: A quantitative multi-study survey of literature data. J. Agric. Sci. 154:515-531.

Castro-Montoya, J. M., N. Peiren, J. Veneman, B. De Baets, S. De Campeneere, and V. Fievez. 2016b. Predictions of methane emission levels and categories based on milk fatty acid profiles from dairy cows. Animal 7:1153-1162.

Chilliard, Y., C. Martin, J. Rouel, and M. Doreau. 2009. Milk fatty acids in dairy cows fed whole crude linseed, extruded linseed, or linseed oil, and their relationship with methane output. J. Dairy Sci. 92:5199-5211.

Chung, Y. H., M. L. He, S. M. McGinn, T. A. McAllister, and K. A. Beauchemin. 2011. Linseed suppresses enteric methane emissions from cattle fed barley silage, but not from those fed grass hay. Anim. Feed Sci. Technol. 166-67:321-329.

Clark, H. 2013. Nutritional and host effects on methanogenesis in the grazing ruminant. Animal 7:41-48.

Derno, M., H. G. Elsner, E. A. Paetow, H. Scholze, and M. Schweigel. 2009. Technical note: A new facility for continuous respiration measurements in lactating cows. J. Dairy Sci. 92:2804-2808.

Dijkstra, J., S. van Gastelen, E. C. Antunes-Fernandes, D. Warner, B. Hatew, G. Klop, S. C. Podesta, H. J. van Lingen, K. A. Hettinga, and A. Bannink. 2016. Relationships between milk fatty acid profiles and enteric methane production in dairy cattle fed grass- or grass silage-based diets. Anim. Prod. Sci. 56:541-548. 
Dijkstra, J., S. M. van Zijderveld, J. A. Apajalahti, A. Bannink, W. J. J. Gerrits, J. R. Newbold, H. B. Perdok, and H. Berends. 2011. Relationships between methane production and milk fatty acid profiles in dairy cattle. Anim. Feed Sci. Technol. 166-167:590-595.

Engelke, S. W., G. Daş, M. Derno, A. Tuchscherer, W. Berg, B. Kuhla, and C. C. Metges. 2018. Milk fatty acids estimated by mid-infrared spectroscopy and milk yield can predict methane emissions in dairy cows. Agron. Sustain. Dev. 38:27.

Enjalbert, F., S. Combes, A. Zened, and A. Meynadier. 2017. Rumen microbiota and dietary fat: A mutual shaping. J. Appl. Microbiol. 123:782-797.

Ferlay, A., M. Doreau, C. Martin, and Y. Chilliard. 2013. Effects of incremental amounts of extruded linseed on the milk fatty acid composition of dairy cows receiving hay or corn silage. J. Dairy Sci. 96:6577-6595.

Firl, N., H. Kienberger, and M. Rychlik. 2014. Validation of the sensitive and accurate quantitation of the fatty acid distribution in bovine milk. Int. Dairy J. 35:139-144.

Gerber, P. J., B. Henderson, and H. P. S. Makkar. 2013. Mitigation of greenhouse gas emissions in livestock production: A review of technical options for non- $\mathrm{CO}_{2}$ emissions. Pages $37-38$ in FAO Animal Production and Health Paper. FAO, Rome, Italy.

German Federal Law Gazette. (Bundesgesetzblatt (BGBl). 1981. Futtermittelverordnung (FuttMV) in der Fassung der Bekanntmachung vom 29. August 2016 (BGBl. I S. 2004), die zuletzt durch Artikel 2 der Verordnung vom 18. Juli 2018 (BGBl. I S. 1219) geändert worden ist/ Feed regulation last updated 18 July 2018. Berlin, Germany.

Gesellschaft für Ernährungsphysiologie. 2001. Empfehlungen zur Energie- und Nährstoffversorgung der Milchkühe und Aufzuchtrinder (Recommended energy and nutrient supply for dairy cows and growing cattle). German Society of Nutrition Physiology/ Ausschuss für Bedarfsnormen, No. 8 ed. DLG-Verlag, Frankfurt am Main, Germany

Glasser, F., A. Ferlay, and Y. Chilliard. 2008. Oilseed lipid supplements and fatty acid composition of cow milk: A meta-analysis. J. Dairy Sci. 91:4687-4703.

Grainger, C., and K. A. Beauchemin. 2011. Can enteric methane emissions from ruminants be lowered without lowering their production? Anim. Feed Sci. Technol. 166-167:308-320.

Hammond, K., L. A. Crompton, A. Bannink, J. Dijkstra, D. R. YanezRuiz, P. O'Kiely, E. Kebreab, M. A. Eugene, Z. Yu, K. J. Shingfield, A. Schwarm, A. N. Hristov, and C. K. Reynolds. 2016. Review of current in vivo measurement techniques for quantifying enteric methane emission from ruminants. Anim. Feed Sci. Technol. 219:13-30.

Hart, K. J., J. A. Huntington, R. G. Wilkinson, C. G. Bartram, and L. A. Sinclair. 2015. The influence of grass silage-to-maize silage ratio and concentrate composition on methane emissions, performance and milk composition of dairy cows. Animal 9:983-991.

Hook, S. E., A. D. G. Wright, and B. W. McBride. 2010. Methanogens: Methane producers of the rumen and mitigation strategies. Archaea 2010:945785.

Hristov, A. N., J. Oh, C. Lee, R. Meinen, F. Montes, T. Ott, J. Firkins, A. Rotz, C. Dell, A. Adesogan, W. Yang, J. Tricarico, E. Kebreab, G. Waghorn, J. Dijkstra, and S. Oosting. 2013. Mitigation of Greenhouse Gas Emissions in Livestock Production: A Review of Technical Options for non- $\mathrm{CO}_{2}$ Emissions. P. J. Gerber, B. Henderson, and H. P. S. Makkar, ed. FAO, Rome, Italy.

Kaps, M., and W. Lamberson. 2004. Biostatistics for Animal Science. CABI Publishing, Wallingford, United Kingdom.

Kliem, K. E., D. J. Humphries, C. K. Reynolds, R. Morgan, and D. I. Givens. 2017. Effect of oilseed type on milk fatty acid composition of individual cows, and also bulk tank milk fatty acid composition from commercial farms. Animal 11:354-364.

Kliem, K. E., R. Morgan, D. J. Humphries, K. J. Shingfield, and D. I. Givens. 2008. Effect of replacing grass silage with maize silage in the diet on bovine milk fatty acid composition. Animal $2: 1850-1858$.
Kliem, K. E., and K. J. Shingfield. 2016. Manipulation of milk fatty acid composition in lactating cows: Opportunities and challenges. Eur. J. Lipid Sci. Technol. 118:1661-1683.

Knapp, J. R., G. L. Laur, P. A. Vadas, W. P. Weiss, and J. M. Tricarico. 2014. Invited review: Enteric methane in dairy cattle production: Quantifying the opportunities and impact of reducing emissions. J. Dairy Sci. 97:3231-3261.

Lanier, J. S., and B. A. Corl. 2015. Challenges in enriching milk fat with polyunsaturated fatty acids. J. Anim. Sci. Biotechnol. 6:2635.

Livingstone, K. M., D. J. Humphries, P. Kirton, K. E. Kliem, D. I. Givens, and C. K. Reynolds. 2015. Effects of forage type and extruded linseed supplementation on methane production and milk fatty acid composition of lactating dairy cows. J. Dairy Sci. 98:4000-4011.

Maia, M. R. G., L. C. Chaudhary, L. Figueres, and R. J. Wallace. 2007. Metabolism of polyunsaturated fatty acids and their toxicity to the microflora of the rumen. Antonie van Leeuwenhoek 91:303-314.

Martin, C., A. Ferlay, P. Mosoni, Y. Rochette, Y. Chilliard, and M. Doreau. 2016. Increasing linseed supply in dairy cow diets based on hay or corn silage: Effect on enteric methane emission, rumen microbial fermentation, and digestion. J. Dairy Sci. 99:3445-3456.

Meignan, T., C. Lechartier, G. Chesneau, and N. Bareille. 2017. Effects of feeding extruded linseed on production performance and milk fatty acid profile in dairy cows: A meta-analysis. J. Dairy Sci. 100:4394-4408.

Mohammed, R., S. M. McGinn, and K. A. Beauchemin. 2011. Prediction of enteric methane output from milk fatty acid concentrations and rumen fermentation parameters in dairy cows fed sunflower, flax, or canola seeds. J. Dairy Sci. 94:6057-6068.

Moraes, L. E., A. B. Strathe, J. G. Fadel, D. P. Casper, and E. Kebreab. 2014. Prediction of enteric methane emissions from cattle. Glob. Chang. Biol. 20:2140-2148.

Naumann, C., R. Bassler, R. Seibold, and C. Barth. 1976. Methodenbuch III: Die chemische Untersuchung von Futtermitteln/ Method book III: Chemical analysis of feedstuffs. VDLUFA, Verlag, Darmstadt, Germany.

Negussie, E., Y. de Haas, F. Dehareng, R. J. Dewhurst, J. Dijkstra, N. Gengler, D. P. Morgavi, H. Soyeurt, S. van Gastelen, T. Yan, and F. Biscarini. 2017. Invited review: Large-scale indirect measurements for enteric methane emissions in dairy cattle: A review of proxies and their potential for use in management and breeding decisions. J. Dairy Sci. 100:2433-2453.

Patra, A. K. 2016. Recent advances in measurement and dietary mitigation of enteric methane emissions in ruminants. Front. Vet. Sci. $3: 39$.

Pickering, N. K., V. H. Oddy, J. Basarab, K. Cammack, B. Hayes, R. S. Hegarty, J. Lassen, J. C. McEwan, S. Miller, C. S. Pinares-Patino, and Y. de Haas. 2015. Animal board invited review: Genetic possibilities to reduce enteric methane emissions from ruminants. Animal 9:1431-1440.

Reynolds, C. K. 2006. Production and metabolic effects of site of starch digestion in dairy cattle. Anim. Feed Sci. Technol. 130:78-94.

Rico, D. E., P. Y. Chouinard, F. Hassanat, C. Benchaar, and R. Gervais. 2016. Prediction of enteric methane emissions from Holstein dairy cows fed various forage sources. Animal 10:203-211.

Shingfield, K. J., M. Bonnet, and N. D. Scollan. 2013. Recent developments in altering the fatty acid composition of ruminant-derived foods. Animal 7:132-162.

Spiekers, H., H. Nußbaum, and V. Potthast. 2009. Erfolgreiche Milchviehfütterung/ Successful feeding of dairy cattle. DLG-Verlag, Frankfurt am Main, Germany.

Sterk, A., B. E. O. Johansson, H. Z. H. Taweel, M. Murphy, A. M. van Vuuren, W. H. Hendriks, and J. Dijkstra. 2011. Effects of forage type, forage to concentrate ratio, and crushed linseed supplementation on milk fatty acid profile in lactating dairy cows. J. Dairy Sci. 94:6078-6091.

van Gastelen, S., E. C. Antunes-Fernandes, K. A. Hettinga, and J. Dijkstra. 2017. Relationships between methane emission of Holstein 
Friesian dairy cows and fatty acids, volatile metabolites and nonvolatile metabolites in milk. Animal 11:1539-1548.

van Gastelen, S., E. C. Antunes-Fernandes, K. A. Hettinga, G. Klop, S. J. J. Alferink, W. H. Hendriks, and J. Dijkstra. 2015. Enteric methane production, rumen volatile fatty acid concentrations, and milk fatty acid composition in lactating Holstein-Friesian cows fed grass silage- or corn silage-based diets. J. Dairy Sci. 98:1915-1927.

van Gastelen, S., and J. Dijkstra. 2016. Prediction of methane emission from lactating dairy cows using milk fatty acids and midinfrared spectroscopy. J. Sci. Food Agric. 96:3963-3968.

van Lingen, H. J., L. A. Crompton, W. H. Hendriks, C. K. Reynolds, and J. Dijkstra. 2014. Meta-analysis of relationships between enteric methane yield and milk fatty acid profile in dairy cattle. J. Dairy Sci. 97:7115-7132.

Van Soest, P. J., J. B. Robertson, and B. A. Lewis. 1991. Methods for dietary fiber, neutral detergent fiber, and nonstarch polysaccharides in relation to animal nutrition. J. Dairy Sci. 74:3583-3597.

Vanrobays, M. L., C. Bastin, J. Vandenplas, H. Hammami, H. Soyeurt, A. Vanlierde, F. Dehareng, E. Froidmont, and N. Gengler. 2016. Changes throughout lactation in phenotypic and genetic correlations between methane emissions and milk fatty acid contents predicted from milk mid-infrared spectra. J. Dairy Sci. 99:7247-7260.

Vlaeminck, B., V. Fievez, A. R. J. Cabrita, A. J. M. Fonseca, and R. J. Dewhurst. 2006. Factors affecting odd- and branched-chain fatty acids in milk: A review. Anim. Feed Sci. Technol. 131:389-417.
Vlaeminck, B., R. Gervais, M. M. Rahman, F. Gadeyne, M. Gorniak, M. Doreau, and V. Fievez. 2015. Postruminal synthesis modifies the odd- and branched-chain fatty acid profile from the duodenum to milk. J. Dairy Sci. 98:4829-4840.

Weill, P., G. Chesneau, Y. Chilliard, M. Doreau, and C. Martin, inventors. 2009. Method for evaluating the amount of methane produced by a dairy ruminant and method for decreasing and controlling this amount. WO 2009/156453 A1. https://patents .google.com/patent/WO2009156453A1/en. Assignee: Valorisation Par Extrusion.

Williams, S. R. O., P. J. Moate, M. H. Deighton, M. C. Hannah, and W. J. Wales. 2014. Methane emissions of dairy cows cannot be predicted by the concentrations of C8:0 and total C18 fatty acids in milk. Anim. Prod. Sci. 54:1757-1761.

Yan, T., C. S. Mayne, F. G. Gordon, M. G. Porter, R. E. Agnew, D. C. Patterson, C. P. Ferris, and D. J. Kilpatrick. 2010. Mitigation of enteric methane emissions through improving efficiency of energy utilization and productivity in lactating dairy cows. J. Dairy Sci 93:2630-2638.

Zehetmeier, M. J. Baudracco, H. Hoffmann, and A. Heissenhuber. 2012. Does increasing milk yield per cow reduce greenhouse gas emissions? A system approach. Animal 6:154-166. 